\title{
A Stackelberg-population competition model via variational inequalities and fixed points
}

\author{
YUE-TIAN ZHAN, XUE-SONG LI and NAN-JING HUANG
}

\begin{abstract}
.
In this paper, we introduce and study a new Stackelberg-population competition model which captures the desired features of both population games and Stackelberg competition model within the same framework. We obtain some characterization results for the Stackelberg-population equilibrium response set and the Stackelberg-population equilibrium leader set by using the variational inequality technique and Brouwer's fixed point theorem. We also show an existence theorem of Nash equilibrium for Stackelbergpopulation competition model under some mild conditions. Finally, we give an example to illustrate our main results.
\end{abstract}

Acknowledgments. This work was supported by the National Natural Science Foundation of China (11471230, 11671282).

The authors are grateful to the editors and the referees for their valuable comments and suggestions.

\section{REFERENCES}

[1] Amir, R. and Grilo, I., Stackelberg versus Cournot Equilibrium, Games Econ. Behav., 26(1999), 1-21

[2] Arieli, I. and Young, H. P., Fast convergence in population games, Department of economics Discussion Paper Series, University of Oxford, 2011

[3] Askar, S. S., Tripoly Stackelberg game model: One leader versus two followers, Appl. Math. Compu., 328 (2018), 301-311

[4] Aubin, J. P. and Ekeland, I., Applied Nonlinear Analysis, Wiley, New York, 1984

[5] Balder, E. J., A unifying pair of Cournot-Nash equilibrium existence results, J. Econ. Th., 102 (2002), 437-470

[6] Blume, L. E., Population Games, In: Arthur, W.B., Durlauf, S.N. and Lane, D. A. (eds), The Economy as an Evolving Complex System II, pp. 425-460, Santa Fe Institute, Santa Fe, 1997

[7] D'Amato, E., Daniele, E., Mallozzi, L., Petrone, G. and Tancredi, S., A hierarchical multiModal hybrid Stackelberg-Nash GA for a leader with multiple followers game, In: Dynamics of Information Systems: Mathematical Foundations, pp. 267-280, Springer, New York, 2012

[8] Eshel, I. and Sansone, E., Evolutionary and dynamic stability in continuous population games, J. Math. Biol, 46 (2003), 445-459

[9] Facchinei, F. and Pang, J.S., Finite-Dimensional Variational Inequalities and Complementarity Problems, I and II, Springer, Berlin, 2003

[10] Glowinski, R., Lions, J. L. and Tremolieres, R., Numerical Analysis of Variational Inequalities, North-Holland, Amsterdam, 1981

[11] Gürsoy, F., Karakaya, V. and Rhoades, B. E., Data dependence results of new multi-step and S-iterative schemes for contractive-like operators, Fixed Point Theory Appl 2013 (2013): 76, https://doi.org/10.1186/1687-18122013-76

Received: 05.11.2019; In revised form: 31.01.2020; Accepted: 07.02.2020

2010 Mathematics Subject Classification. 90C30, 91B52, 49J40.

Key words and phrases. Stackelberg-population competition model, Nash equilibrium, variational inequality, fixed point, projection.

Corresponding author: Nan-jing Huang; nanjinghuang@hotmail.com 
[12] Han, Y. and Huang, N. J., Existence and stability of solutions for a class of generalized vector equilibrium problems, Positivity, 20 (2016), 829-846

[13] Julien, L. A., A note on Stackelberg competition, J. Econ., 103 (2011), 171-187

[14] Kicsiny, R., Varga, Z. and Scarelli, A., Backward induction algorithm for a class of closed-loop Stackelberg games, Eur. J. Oper. Res., 237 (2014), 1021-1036

[15] Lanni, A., Learning correlated equilibria in population games, Math. Social Sci., 42 (2001), 271-294

[16] Lahkar, R., Large population aggregative potential games, Dyn. Games Appl., 7 (2017), 443-467

[17] Lee, S. and Yi, Y., Distributed sharing of base stations for greening: a population game approach, In: Cheng J., Hossain E., Zhang H., Saad W., Chatterjee M. (eds) Game Theory for Networks, GameNets 2016, Lecture Notes of the Institute for Computer Sciences, Social Informatics and Telecommunications Engineering, vol 174. Springer, Cham, pp. 79-89

[18] Lu, J., Xiao, Y. B. and Huang, N. J., A Stackelberg quasi-equilibrium problem via quasi-variational inequalities, Carpathian J. Math., 34 (2018), 355-362

[19] Lu, J., Zhou, L. W., Xiao, Y. B. and Huang, N. J., A nonsmooth Stackelberg equilibrium problem via mixed variational inequalities, Carpathian J. Math., 35 (2019), 339-347

[20] Miachael, E., Continuous selections, Annas of Math., 63 (1956), 361-382

[21] Moskovitz, D. and Dines, L. L., Convexity in a linear space with an inner product, Duke Math. J., 5 (1939), 520-534

[22] Nagy, S., Stackelberg equilibria via variational inequalities and projections, J. Global Optim., 57 (2013), 821-828

[23] Nash, J., Non-cooperative games, Annals of Math., 54 (1951), 286-295

[24] Novak, A. J., Feichtinger, G. and Leitmann, G., A differential game related to terrorism: nash and stackelberg strategies, J. Optim. Theory Appl., 144 (2010), 533-555

[25] Reluga, T. C. and Galvani, A. P., A general approach for population games with application to vaccination, Math. Biosci, 230 (2011), 67-78

[26] Sandholm, W. H., Negative externalities and evolutionary implementation, Rev. Eco. Stud., 72 (2005), 885-915

[27] Sandholm, W. H., Large population potential games, J. Econ. Th., 144 (2009), 1710-1725

[28] Sandholm, W. H., Population Games and Evolutionary Dynamicss, The MIT Press, Cambridge, Massachusetts, London, England, 2010

[29] Yang, G. H., Yang, H. and Song, Q. Q., Stability of weighted Nash equilibria for multiobjective population games, J. Nonlinear Sci. Appl., 9 (2016), 4167-4176

[30] Yang, G. H. and Yang, H., Stability of weakly Pareto-Nash equilibria and Pareto-Nash equilibria for multiobjective population games, Set-Valued Var. Anal., 25 (2017), 427-439

\author{
SICHUAN UNIVERSITY \\ DEPARTMENT OF MATHEMATICS \\ WANGJIANG ROAD 29, 610064, CHENGDU, P. R. CHINA \\ Email address: 759025926 @qq. com \\ Email address: xuesongli78@hotmail.com \\ Email address: nanjinghuang@hotmail.com
}

